\title{
Use of the novel phylogenetic marker dnaJ and DNA-DNA hybridization to clarify interrelationships within the genus Aeromonas
}

\author{
Pham Hong Nhung, ${ }^{1}$ Hiroyuki Hata, ${ }^{1}$ Kiyofumi Ohkusu, ${ }^{1}$ Makiko Noda, ${ }^{1}$ \\ Mohammad Monir Shah, ${ }^{1}$ Keiichi Goto ${ }^{2}$ and Takayuki Ezaki ${ }^{1}$ \\ ${ }^{1}$ Department of Microbiology, Regeneration and Advanced Medical Science, Gifu University \\ Graduate School of Medicine, 1-1 Yanagido, Gifu 501-1194, Japan \\ ${ }^{2}$ Food Research Laboratories, Mitsui Norin Co. Ltd, 223-1 Miyahara, Fujieda, \\ Shizuoka 426-0133, Japan
}

Correspondence

Pham Hong Nhung

hongnhung_gifu@yahoo.com

\begin{abstract}
The interrelationships of 27 Aeromonas strains were investigated using dnaJ sequences and DNA-DNA hybridization. dnaJ sequence similarities showed a stronger relationship with DNA-DNA relatedness values than did 16S rRNA gene sequence similarities. Additionally, $d n a J$ sequence analysis, with interspecies divergence over $5.2 \%$ in most cases, gave better resolution than 16S rRNA gene sequences for the differentiation of strains at the species level. Relationships among Aeromonas species were therefore elucidated on the basis of dnaJ sequences and DNA-DNA reassociation. Strains of Aeromonas encheleia and Aeromonas sp. HG11 were unquestionably grouped in the same genetic species, since they shared $98.7 \%$ dnaJ sequence similarity and $82-85 \%$ genomic relatedness. The phylogenetically close relationships obtained from $d n a J$ sequence analysis (1.7-3.3\% genetic distance) were corroborated by high DNA-DNA relatedness (73-97\%) to support the previous suggestion that Aeromonas culicicola and Aeromonas allosaccharophila are later heterotypic synonyms of Aeromonas veronii. Our findings will contribute to the clarification of controversial relationships in the genus Aeromonas and also demonstrate that analysis of $d n a J$ sequences can be a powerful tool for interspecies study of the genus.
\end{abstract}

\section{INTRODUCTION}

The taxonomy of the genus Aeromonas has been the subject of considerable debate. In this genus, taxonomic controversies have been attributed to the absence of sufficient phenotypic markers for the differentiation of all recognized DNA hybridization groups (HGs) and to the striking disagreement between DNA HGs and their phylogenetic positions (Martínez-Murcia, 1999). According to the second edition of Bergey's Manual of Systematic Bacteriology, the genus includes 14 phenospecies that correspond to at least 17 DNA HGs (Martin-Carnahan \& Joseph, 2005). Recently, descriptions of novel species, reclassifications and extended descriptions of species with validly published names have resulted in ongoing changes to the taxonomy of the genus Aeromonas.

At present, DNA-DNA hybridization and 16S rRNA gene sequences, along with housekeeping gene sequences, are

The GenBank/EMBL/DDBJ accession numbers for the partial dnaJ gene sequences reported in this study are AB280551-AB280578, as indicated in Fig. 1. considered crucial molecular tools for the definition of bacterial species (Stackebrandt et al., 2002). In the genus Aeromonas, however, the high conservation of the 16S rRNA gene sequence (97.8-100\%; Martin-Carnahan \& Joseph, 2005) and the existence of several copies of the gene, with intragenomic heterogeneity, in some Aeromonas strains (Morandi et al., 2005) limit the usefulness of the 16S rRNA gene for taxonomic analysis at the species level. DNA-DNA hybridization has not been subjected to extensive analysis of interrelationships for all present species. Moreover, discordances between 16S rRNA gene analysis and DNA-DNA hybridization results (Martínez-Murcia et al., 1992b) or between DNA-DNA hybridization data reported by different authors (Saavedra et al., 2006) have added more fuel to the controversies regarding the sites of Aeromonas species boundaries. It has been reported that housekeeping gene sequences, e.g. gyrB and $r p o D$, could be used to clarify interspecies phylogenetic relationships within Aeromonas (Yáñez et al., 2003; Soler et al., 2004). In some cases, the different behaviour of $g y r B$ and $r p o D$ sequences has left species delineations (e.g. Aeromonas culicicola and Aeromonas allosaccharophila) in an ambiguous state, so they still need to be resolved (Saavedra et al., 2006). 
The dnaJ gene, encoding heat-shock protein 40, which acts as a functional cohort of DnaK in various aspects of protein dynamics (Caplan et al., 1993), has been reported to be a suitable target for phylogenetic study and identification of species of Mycobacterium (Takewaki et al., 1994), Legionella (Liu et al., 2003) and Streptococcus (Itoh et al., 2006). In this study, we used dnaJ gene sequences and extensive DNADNA hybridizations in an attempt to clear up the taxonomic confusion regarding interrelationships within the genus Aeromonas.

\section{METHODS}

Bacterial strains. The 27 strains used were obtained from the Gifu Type Culture Collection, Gifu University, Japan, and are listed in Fig. 1. Strains were grown on tryptic soy agar (Difco) at $28^{\circ} \mathrm{C}$, except for the psychrotolerant Aeromonas salmonicida strains, which were grown at room temperature.

Primer design. No dnaJ sequences from Aeromonas strains were available in GenBank. Therefore, the first primers were designed from conserved regions of sequences from species related to Aeromonas (Vibrio cholerae, Vibrio harveyi, Escherichia coli, Salmonella enterica subsp. enterica and Pseudomonas putida; GenBank accession numbers AE004171, AY639008, M12565, U58360 and AY823737, respectively). Based on sequences of Aeromonas strains amplified by the first primers, primers Aero-dnaJF (5'-CGAGATCAAGAAGGCGTACAAG- $3^{\prime}$ ) and Aero-dnaJR3 (5'-CACCACCTTGCACATCAGATC- $3^{\prime}$ ) were designed to amplify a $d n a J$ fragment of approximately 934 bp.

PCR amplification and sequencing. DNA was extracted by quick-heat lysis. One colony was suspended in $100 \mu \mathrm{l}$ distilled water and boiled for $10 \mathrm{~min}$. The supernatant served as a template. Amplification reactions contained $1 \times$ PCR buffer, $0.2 \mathrm{mM}$ of each $\mathrm{dNTP}$,
$0.1 \mathrm{U}$ Taq polymerase (Takara Shuzo), $0.4 \mu \mathrm{M}$ of each primer and $1 \mu \mathrm{l}$ template in a final reaction volume of $20 \mu \mathrm{l}$. PCR amplification was carried out in a GeneAmp PCR system 9700 thermal cycler (Applied Biosystems) as follows: a $3 \mathrm{~min}$ initial denaturation step at $94{ }^{\circ} \mathrm{C}$, followed by 35 cycles at $94{ }^{\circ} \mathrm{C}$ for $30 \mathrm{~s}, 60^{\circ} \mathrm{C}$ for $30 \mathrm{~s}$ and $74^{\circ} \mathrm{C}$ for $1 \mathrm{~min}$, with a final extension step of $7 \mathrm{~min}$ at $72{ }^{\circ} \mathrm{C}$. Amplified products were examined by agarose gel electrophoresis $(1.2 \%)$ and ethidium bromide staining. Purified PCR products were sequenced with the use of a BigDye Terminator v3.1 cycle sequencing ready reaction kit (Applied Biosystems) in an ABI PRISM 3100 Genetic Analyzer (Applied Biosystems) according to the manufacturer's instructions.

Phylogenetic data analysis. $d n a J$ sequences were aligned by the CLUSTAL W program (version 1.83) (Thompson et al., 1994). Genetic distances were obtained with the MEGA3 package (Kumar et al., 2004) by the neighbour-joining method (Saitou \& Nei, 1987) and Kimura's two-parameter distance model (Kimura, 1980). Phylogenetic trees were constructed by the neighbour-joining and maximumparsimony methods.

DNA-DNA hybridization. A total of 21 strains were selected for the DNA-DNA reassociation study. Genomic DNA was prepared using the protocol of Marmur (1961) with minor modifications (Ezaki et al., 1988). DNA-DNA hybridizations were carried out at an optimal temperature of $45^{\circ} \mathrm{C}$ in $2 \times$ SSC buffer and $50 \%$ formamide, using the fluorometric microplate method (Ezaki et al., 1989).

\section{RESULTS AND DISCUSSION}

\section{Analysis of dnaJ sequences and DNA-DNA hybridization}

Partial dnaJ gene fragments of approximately 934 bp were amplified for all 27 Aeromonas strains. dnaJ sequences from

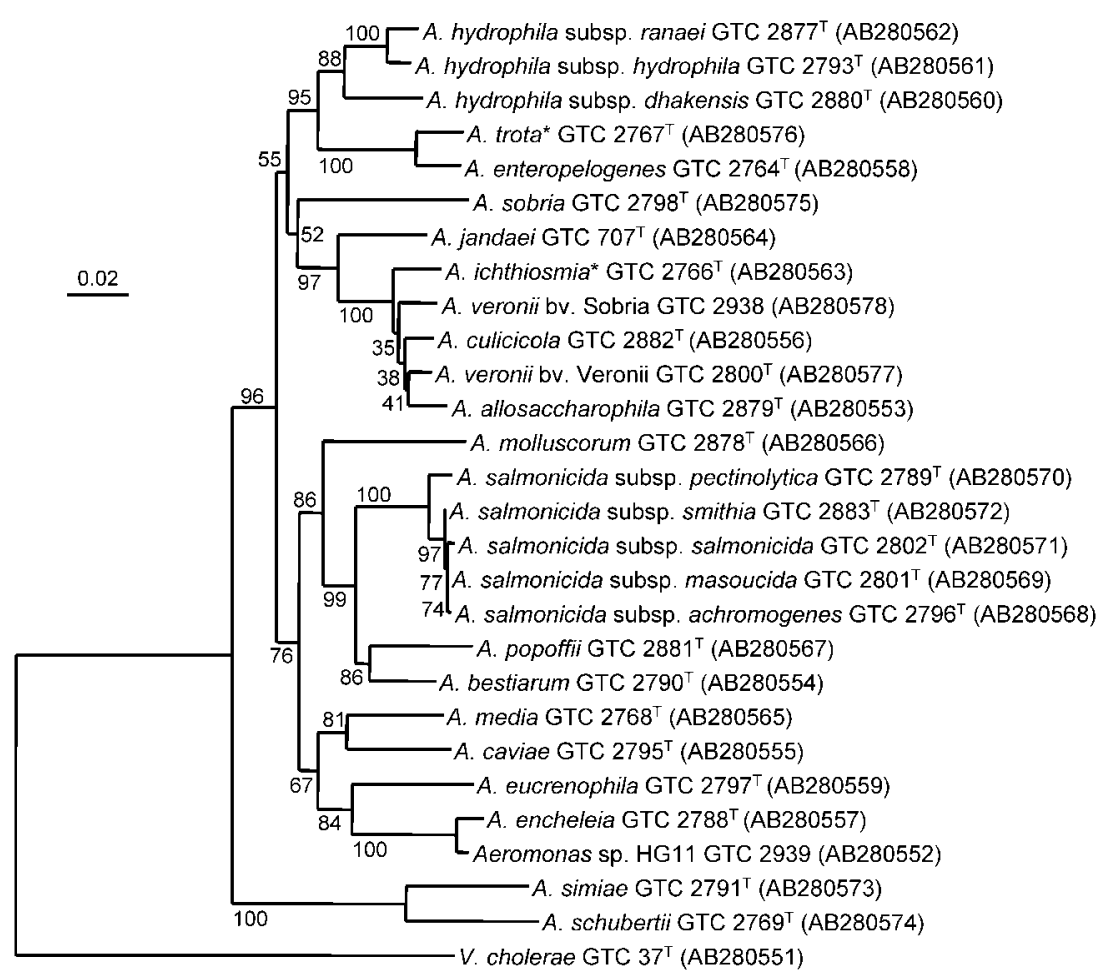

Fig. 1. Neighbour-joining phylogenetic tree based on partial dnaJ (891 bp) gene sequences of 27 Aeromonas strains. Bootstrap values (expressed as percentages of 1000 replicates) are shown at nodes. Vibrio cholerae GTC $37^{\top}$ was used as an outgroup. Bar, $2 \%$ sequence divergence. Numbers in parentheses indicate the dnaJ accession numbers. Asterisks indicate sequences from $A$. trota and $A$. ichthiosmia, which are now considered to be synonyms of $A$. enteropelogenes and $A$. veronii. 
all the strains were aligned and DNA sequence similarities were calculated for a consecutive stretch of 891 bases. Mean sequence similarity, defined as discriminatory power ( $\mathrm{La}$ Scola et al., 2003), was $89.2 \%$, indicating a divergence of the dnaJ gene that is remarkably greater than that of the $16 \mathrm{~S}$ rRNA gene $(98.7 \%)$, but comparable to that of $g y r B$ $(92.2 \%)$ and $r p o D(89.3 \%)$ (Soler et al., 2004). Sequence similarity among the Aeromonas strains ranged from 81.2 to $99.9 \%$, corresponding to between 167 and 1 nucleotide differences.

At the intraspecies level, the rate of nucleotide substitution did not exceed $3.3 \%$, except for Aeromonas hydrophila subsp. dhakensis GTC $2880^{\mathrm{T}}$, which showed far larger distances (4.7 and 5.1\%, respectively) from A. hydrophila subsp. hydrophila GTC $2793^{\mathrm{T}}$ and A. hydrophila subsp. ranaei GTC $2877^{\mathrm{T}}$. At the interspecies level, the rate of nucleotide substitutions was greater than $5.2 \%$ for most Aeromonas strain pairs but was only 1.7-3.3\% for a cluster including four species (Aeromonas ichthiosmia, Aeromonas veronii, A. allosaccharophila and A. culicicola) and $1.3 \%$ for Aeromonas encheleia and Aeromonas sp. HG 11. These results brought into question the species delineations of A. culicicola, A. allosaccharophila and Aeromonas sp. HG11.
The phylogeny based on dnaJ sequences of 27 strains constructed by the neighbour-joining method is shown in Fig. 1. The tree generated by the maximum-parsimony method gave the same topology (data not shown). In general, the relationships based on $d n a J$ sequences were in relatively good agreement with those based on $16 \mathrm{~S}$ rRNA gene sequences. However, some of the relationships on the 16S rRNA tree were markedly different from those on the dnaJ tree. In terms of the dnaJ gene, all A. hydrophila subspecies were in a monophyletic group, although their substitution rates fell in a rather wide range $(1.8-5.1 \%)$, and their allocations were reliable as supported by high bootstrap values. This was in contrast to the $16 \mathrm{~S}$ rRNA tree, on which A. hydrophila subsp. dhakensis belonged to a separate cluster from the remaining $A$. hydrophila subspecies (Miñana-Galbis et al., 2004). A. allosaccharophila was closely related to $A$. veronii on the $d n a J$ phylogeny but was located in a lineage far from $A$. veronii on the $16 \mathrm{~S}$ rRNA tree.

Hybridization results are presented in Table 1. Each value was the mean of triplicate experiments. Repeated experiments exhibited a maximum standard deviation of $4 \%$. In agreement with the published proposals that $A$. ichthiosmia and Aeromonas enteropelogenes are respectively considered

Table 1. Results of DNA-DNA hybridization expressed as percentage DNA relatedness

DNA-DNA hybridization values greater than or equal to $70 \%$ are in bold.

\begin{tabular}{|c|c|c|c|c|c|c|c|c|c|c|c|c|c|c|c|c|c|c|c|c|c|}
\hline \multirow[t]{2}{*}{ Strain } & \multicolumn{21}{|c|}{ Hybridization (\%) with labelled reference DNA from strain: } \\
\hline & 1 & 2 & 3 & 4 & 5 & 6 & 7 & 8 & 9 & 10 & 11 & 12 & 13 & 14 & 15 & 16 & 17 & 18 & 19 & 20 & 21 \\
\hline 1. A. culicicola GTC $2882^{\mathrm{T}}$ & 100 & 97 & 88 & 85 & 81 & 51 & 54 & 55 & 45 & 43 & 49 & 44 & 45 & 41 & 54 & 48 & 45 & 43 & 38 & 32 & 32 \\
\hline 2. A. veronii bv. Veronii GTC $2800^{\mathrm{T}}$ & 94 & 100 & 94 & 90 & 82 & 64 & 67 & 61 & 59 & 55 & 52 & 48 & 60 & 46 & 61 & 51 & 58 & 61 & 41 & 35 & 38 \\
\hline 3. A. veronii bv. Sobria GTC 2938 & 91 & 93 & 100 & 83 & 73 & 61 & 63 & 66 & 47 & 49 & 49 & 43 & 51 & 42 & 60 & 50 & 55 & 52 & 46 & 25 & 35 \\
\hline 4. A. ichthiosmia GTC $2766^{\mathrm{T}}$ & 75 & 94 & 83 & 100 & 70 & 62 & 67 & 48 & 49 & 48 & 60 & 50 & 54 & 35 & 53 & 44 & 55 & 60 & 35 & 37 & 29 \\
\hline 5. A. allosaccharophila GTC $2879^{\mathrm{T}}$ & 87 & 86 & 75 & 67 & 100 & 59 & 50 & 53 & 47 & 38 & 54 & 47 & 42 & 38 & 48 & 37 & 48 & 39 & 35 & 31 & 27 \\
\hline 6. A. sobria GTC $2798^{\mathrm{T}}$ & 66 & 61 & 64 & 63 & 64 & 100 & 62 & 68 & 57 & 47 & 50 & 51 & 64 & 38 & 57 & 48 & 53 & 60 & 39 & 38 & 32 \\
\hline 7. A. jandaei GTC $707^{\mathrm{T}}$ & 59 & 67 & 62 & 60 & 53 & 48 & 100 & 64 & 47 & 49 & 55 & 46 & 52 & 40 & 53 & 43 & 52 & 55 & 39 & 35 & 34 \\
\hline 8. A. enteropelogenes GTC $2764^{\mathrm{T}}$ & 55 & 58 & 63 & 50 & 44 & 50 & 49 & 100 & 87 & 47 & 55 & 46 & 49 & 51 & 57 & 56 & 52 & 47 & 50 & 39 & 44 \\
\hline 9. A. trota GTC $2767^{\mathrm{T}}$ & 58 & 60 & 60 & 53 & 58 & 47 & 56 & 82 & 100 & 52 & 44 & 45 & 58 & 45 & 59 & 50 & 58 & 59 & 40 & 37 & 43 \\
\hline 10. A. bestiarum GTC $2790^{\mathrm{T}}$ & 49 & 57 & 57 & 43 & 45 & 46 & 48 & 55 & 49 & 100 & 81 & 72 & 61 & 53 & 62 & 53 & 56 & 58 & 42 & 37 & 37 \\
\hline 11. A. popoffii GTC $2881^{\mathrm{T}}$ & 45 & 54 & 56 & 64 & 46 & 44 & 51 & 63 & 42 & 71 & 100 & 64 & 56 & 46 & 65 & 50 & 60 & 55 & 41 & 34 & 35 \\
\hline $\begin{array}{l}\text { 12. A. salmonicida subsp. salmonicida } \\
\text { GTC } 2802^{\mathrm{T}}\end{array}$ & 37 & 42 & 45 & 40 & 46 & 34 & 47 & 56 & 35 & 68 & 61 & 100 & 52 & 37 & 57 & 53 & 48 & 51 & 41 & 30 & 32 \\
\hline 13. A. encheleia GTC $2788^{\mathrm{T}}$ & 42 & 47 & 46 & 36 & 39 & 39 & 39 & 52 & 44 & 51 & 53 & 54 & 100 & 82 & 66 & 52 & 57 & 47 & 39 & 35 & 34 \\
\hline 14. Aeromonas sp. HG11 GTC 2939 & 42 & 47 & 51 & 45 & 46 & 37 & 46 & 51 & 43 & 57 & 51 & 48 & 85 & 100 & 62 & 56 & 59 & 56 & 51 & 30 & 36 \\
\hline 15. A. eucrenophila GTC $2797^{\mathrm{T}}$ & 54 & 56 & 52 & 53 & 39 & 46 & 50 & 66 & 55 & 54 & 54 & 54 & 67 & 63 & 100 & 59 & 60 & 48 & 52 & 38 & 39 \\
\hline 16. A. caviae GTC $2795^{\mathrm{T}}$ & 51 & 52 & 56 & 48 & 46 & 47 & 53 & 54 & 56 & 57 & 55 & 52 & 60 & 64 & 60 & 100 & 64 & 56 & 39 & 46 & 47 \\
\hline 17. A. media GTC $2768^{\mathrm{T}}$ & 50 & 51 & 49 & 43 & 44 & 38 & 45 & 59 & 42 & 47 & 58 & 52 & 62 & 60 & 54 & 61 & 100 & 51 & 39 & 37 & 35 \\
\hline $\begin{array}{l}\text { 18. A. hydrophila subsp. hydrophila } \\
\text { GTC } 2793^{\mathrm{T}}\end{array}$ & 55 & 58 & 64 & 55 & 45 & 45 & 54 & 61 & 53 & 62 & 65 & 66 & 68 & 57 & 67 & 55 & 62 & 100 & 45 & 44 & 44 \\
\hline 19. A. molluscorum GTC $2878^{\mathrm{T}}$ & 38 & 42 & 46 & 34 & 33 & 32 & 40 & 53 & 36 & 37 & 48 & 46 & 48 & 41 & 60 & 41 & 62 & 40 & 100 & 31 & 34 \\
\hline 20. A. simiae GTC $2791^{\mathrm{T}}$ & 30 & 40 & 32 & 29 & 30 & 26 & 31 & 44 & 33 & 30 & 37 & 32 & 36 & 27 & 45 & 36 & 42 & 38 & 37 & 100 & 44 \\
\hline 21. A. schubertii GTC $2769^{\mathrm{T}}$ & 45 & 51 & 46 & 34 & 32 & 33 & 38 & 50 & 43 & 29 & 36 & 40 & 38 & 36 & 49 & 36 & 46 & 40 & 36 & 55 & 100 \\
\hline
\end{tabular}


to be synonyms of A. veronii and Aeromonas trota (Huys et al., 2001, 2002), high genomic relatedness was observed between A. ichthiosmia GTC $2766^{\mathrm{T}}$ and A. veronii strains (83-94\%) as well between A. enteropelogenes GTC $2764^{\mathrm{T}}$ and A. trota GTC $2767^{\mathrm{T}}(82-87 \%)$ (Table 1). DNA-DNA relatedness values in reciprocal hybridizations between $A$. encheleia GTC $2788^{\mathrm{T}}$ and Aeromonas sp. HG11 GTC 2939, between members of the cluster including $A$. veronii, $A$. ichthiosmia, A. allosaccharophila and A. culicicola or between Aeromonas bestiarum, Aeromonas popoffii and A. salmonicida strains were also greater than the $70 \%$ threshold recommended for species delineation. These DNA-DNA hybridization results were in agreement with the phylogenetic relationships observed from the dnaJ tree (Fig. 1).

Scatter plots of pairwise dnaJ (Fig. 2a) and 16S rRNA gene (Fig. 2b) sequence similarities and pairwise DNA-DNA relatedness values show a linear relationship between pairwise dnaJ or 16S rRNA gene sequence similarities and
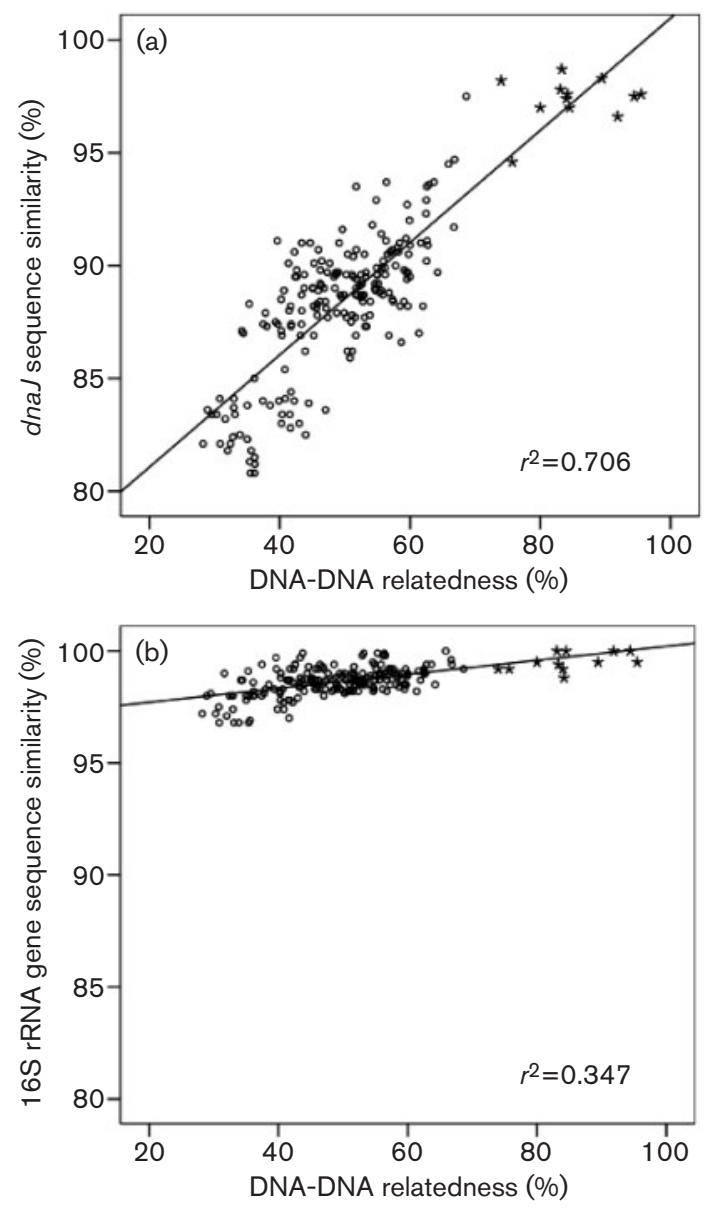

Fig. 2. Scatter plots of DNA-DNA relatedness values against dnaJ (a) and 16S rRNA gene (b) sequence similarities for 21 Aeromonas strains. Each dot represents a pair of strains, plotted according to their genomic relatedness and sequence similarity. Solid lines represent the regression lines. Asterisks indicate DNA-DNA relatedness values greater than $70 \%$.
DNA-DNA relatedness values. Regression analysis showed a stronger relationship between DNA-DNA reassociation values and $d n a J$ sequence similarities $\left(r^{2}=0.706, P<0.001\right)$ than between the former and 16S rRNA gene sequence similarities $\left(r^{2}=0.347, P<0.001\right)$. As a consequence, phylogenetic relationships between Aeromonas species are in close agreement with the current taxonomic classification of this genus. Additionally, the discriminatory power of the dnaJ sequence is greater than that of the $16 \mathrm{~S}$ rRNA gene sequence, enabling dnaJ sequences to differentiate clearly any two species. This highlights the fact that the dnaJ gene is a promising phylogenetic marker in the genus Aeromonas.

\section{Clarification of controversial taxonomic issues}

In the taxonomy of the genus Aeromonas, controversies remain regarding species delineation. Discrepancies between analyses of different phylogenetic markers or between different sets of DNA-DNA hybridization data have led to ambiguities in the allocation of members of Aeromonas to individual species. The present results from $d n a J$ sequence analysis and DNA-DNA hybridization can be expected to contribute to the clarification of the interrelationships between Aeromonas species.

Firstly, on the basis of the high DNA-DNA relatedness obtained in a previous study (75.6\%) (and corroborated in this study; $68-72 \%$ ) and the impossibility of separation by either biochemical tests or 16S rRNA gene sequence, it was suggested previously that A. salmonicida and A. bestiarum might represent a single taxon (Martínez-Murcia et al., 2005). However, housekeeping gene sequence analysis revealed genetic divergence between these two species. gyrB showed nucleotide substitutions $(2.2-3.3 \%)$ on the borderline between the intra- and interspecies ranges (Yáñez et al., 2003), but $r p o D$, with $6.8-8.7 \%$ divergence (Soler et al., 2004), and dnaJ, with 5.2-6.2\% divergence in this study, allowed easy differentiation of A. salmonicida and A. bestiarum as two separate taxa.

To date, one of the most debatable issues within the genus concerns A. encheleia and Aeromonas sp. HG11. Comparison of 16S rRNA gene sequences of A. encheleia and Aeromonas sp. HG11 strains showed that they were genetically different and phylogenetically separate (MartínezMurcia, 1999). In a study on the polymorphism of tRNA intergenic spacers, these two species also presented different tDNA-PCR patterns (Łaganowska \& Kaznowski, 2005). On the other hand, they were found to share similar combined intergenic spacer region (ISR)-RFLP patterns and to constitute one group (Łaganowska \& Kaznowski, 2004). Divergences determined for sequences of gyrB (Yáñez et al., 2003), rpoD (Soler et al., 2004) and dnaJ (in the present study) were respectively $2.1-2.2,1.4-1.7$ and $1.3 \%$. Compared with the intra- and interspecies ranges of sequence divergence observed in the genus Aeromonas, these values fall within limits that suggest that these taxa might represent a single species. DNA-DNA reassociation, the determinate criterion, gave different results. Esteve et al. (1995) showed 
that DNA-DNA relatedness between A. encheleia and Aeromonas sp. HG11 strains was only $12 \%$, whereas Huys et al. (1997a) reported a value of $84 \%$, considerably exceeding the threshold value of $70 \%$ for membership of the same species. Our hybridization data (82-85\%) were comparable to those reported by Huys et al. (1997a). Thus, we suggest that $A$. encheleia and Aeromonas sp. HG11 belong to the same genetic group.

Heated discussion is also taking place with respect to $A$. culicicola and A. allosaccharophila. They were described as two novel Aeromonas species by Pidiyar et al. (2002) and Martínez-Murcia et al. (1992a). In later studies, from evidence deduced from phenotypic characteristics, amplified fragment length polymorphism and DNA-DNA hybridization results, Huys et al. (1996, 2001, 2005) cast doubt on the status of these species as separate from $A$. veronii. However, contradictions between hybridization data from Huys et al. $(2001,2005)$ and from the original descriptions of the three species have resulted in the exact positions of these species in the genus Aeromonas remaining unclear. Study of gyrB and $r p o D$ housekeeping gene sequences (Soler et al., 2004) showed that the nucleotide substitution rates of these species were slightly greater than the intraspecies substitution rate (approx. $2 \%$ ), but it is worth noting that the collection of Aeromonas strains used by Soler et al. (2004) did not include members of the $A$. hydrophila subspecies. When $A$. hydrophila subspecies were added, the highest intrasubspecies substitution rates were increased to $4.4 \%$ for $g y r B$ and $5.1 \%$ for $r p o D$. In our study, strains of A. culicicola and A. allosaccharophila, together with two $A$. veronii biovars and $A$. ichthiosmia (a later synonym of A. veronii), clustered in a very close genetic group. Sequence divergences among them (1.7-3.3\%) were the lowest in comparison with interspecies divergence in the entire genus and were comparable to the intraspecies divergence. The high genomic relatedness (67-97\%; Table 1) observed between the five strains $A$. ichthiosmia GTC $2766^{\mathrm{T}}$, A. culicicola GTC $2882^{\mathrm{T}}$, A. allosaccharophila GTC $2879^{\mathrm{T}}$, A. veronii bv. Veronii GTC $2800^{\mathrm{T}}$ and $A$. veronii bv. Sobria GTC 2938 corroborated the phylogenetic relationships obtained from housekeeping gene analysis, indicating a highly close genetic relationship between them. In terms of the status of A. culicicola and A. allosaccharophila in the genus Aeromonas, Huys et al. $(2001,2005)$ have endeavoured to prove the affiliation of $A$. culicicola and A. allosaccharophila to $A$. veronii by strong phenotypic and genotypic evidence, but the positions of these species remain debatable because of contradictions between sets of DNA-DNA hybridization data and a disagreement between recently published phylogenetic data (Soler et al., 2004; Saavedra et al., 2006). Our DNA-DNA hybridization results and phylogenetic analysis support the results given by Huys et al. $(2001,2005)$ to justify the recognition of $A$. allosaccharophila and $A$. culicicola as later heterotypic synonyms of $A$. veronii.

It should also be noted that, in this study, A. bestiarum GTC $2790^{\mathrm{T}}$ and A. popoffii GTC $2881^{\mathrm{T}}$ showed high DNA-DNA relatedness (71-81\%), which is rather in disagreement with the result given in the original description of $A$. popoffii (53\%; Huys et al., 1997b). Despite the tight relationship, these species were clearly distinguishable on the basis of housekeeping gene sequence divergence (3.0, 4.4 and 5.5\%, respectively, for $g y r B, r p o D$ and $d n a J)$. A likely explanation for the discrepancy observed between sequencing and hybridization data in the case of $A$. bestiarum and $A$. salmonicida or A. bestiarum and A. popoffii is that the measure of DNA sequence relatedness by DNA-DNA hybridization may be too crude, or at least not adequately fine to separate highly related species (Martínez-Murcia et al., 2005).

In conclusion, our findings indicate that analysis of $d n a J$ sequences offers advantages over the 16S rRNA gene in defining phylogenetic relationships within the genus Aeromonas. Results obtained from analyses of $d n a J$ sequences and DNA-DNA hybridization in this study provide additional information on the interrelationships of the genus Aeromonas, allowing greater accuracy and reliability to be obtained. However, additional reference strains for each species are required for validation of the cut-off point of $d n a J$ sequence divergence for species delineation.

\section{REFERENCES}

Caplan, A. J., Cyr, D. M. \& Douglas, M. G. (1993). Eukaryotic homologues of Escherichia coli DnaJ: a diverse protein family that functions with Hsp70 stress proteins. Mol Biol Cell 4, 555-563.

Esteve, C., Gutierréz, M. C. \& Ventosa, A. (1995). Aeromonas encheleia sp. nov., isolated from European eels. Int J Syst Bacteriol 45, 462-466.

Ezaki, T., Takeuchi, N., Liu, S. L., Kai, A., Yamamoto, H. \& Yabuuchi, E. (1988). Small-scale DNA preparation for rapid genetic identification of Campylobacter species without radioisotope. Microbiol Immunol 32, 141-150.

Ezaki, T., Hashimoto, Y. \& Yabuuchi, E. (1989). Fluorometric deoxyribonucleic acid-deoxyribonucleic acid hybridization in microdilution wells as an alternative to membrane filter hybridization in which radioisotopes are used to determine genetic relatedness among bacterial strains. Int J Syst Bacteriol 39, 224-229.

Huys, G., Coopman, R., Janssen, P. \& Kersters, K. (1996). Highresolution genotypic analysis of the genus Aeromonas by AFLP fingerprinting. Int J Syst Bacteriol 46, 572-580.

Huys, G., Kämpfer, P., Altwegg, M., Coopman, R., Janssen, P., Gillis, M. \& Kersters, K. (1997a). Inclusion of Aeromonas DNA hybridization group 11 in Aeromonas encheleia and extended descriptions of the species Aeromonas eucrenophila and A. encheleia. Int J Syst Bacteriol 47, 1157-1164.

Huys, G., Kämpfer, P., Altwegg, M., Kersters, I., Lamb, A., Coopman, R., Lüthy-Hottenstein, J., Vancanneyt, M., Janssen, P. \& Kersters, K. (1997b). Aeromonas popoffii sp. nov., a mesophilic bacterium isolated from drinking water production plants and reservoirs. Int $J$ Syst Bacteriol 47, 1165-1171.

Huys, G., Kämpfer, P. \& Swings, J. (2001). New DNA-DNA hybridization and phenotypic data on the species Aeromonas ichthiosmia and Aeromonas allosaccharophila: A. ichthiosmia Schubert et al. 1990 is a later synonym of A. veronii Hickman-Brenner et al. 1987. Syst Appl Microbiol 24, 177-182. 
Huys, G., Denys, R. \& Swings, J. (2002). DNA-DNA reassociation and phenotypic data indicate synonymy between Aeromonas enteropelogenes Schubert et al. 1990 and Aeromonas trota Carnahan et al. 1991. Int J Syst Evol Microbiol 52, 1969-1972.

Huys, G., Cnockaert, M. \& Swings, J. (2005). Aeromonas culicicola Pidiyar et al. 2002 is a later subjective synonym of Aeromonas veronii Hickman-Brenner et al. 1987. Syst Appl Microbiol 28, 604-609.

Itoh, Y., Kawamura, Y., Kasai, H., Shah, M. M., Nhung, P. H., Yamada, M., Sun, X., Koyana, T., Hayashi, M. \& other authors (2006). dnaJ and gyrB gene sequence relationship among species and strains of genus Streptococcus. Syst Appl Microbiol 29, 368-374.

Kimura, M. (1980). A simple method for estimating evolutionary rates of base substitutions through comparative studies of nucleotide sequences. J Mol Evol 16, 111-120.

Kumar, S., Tamura, K. \& Nei, M. (2004). MEGA3: integrated software for molecular evolutionary genetics analysis and sequence alignment. Brief Bioinform 5, 150-163.

Kaganowska, M. \& Kaznowski, A. (2004). Restriction fragment length polymorphism of 16S-23S rDNA intergenic spacer of Aeromonas spp. Syst Appl Microbiol 27, 549-557.

kaganowska, M. \& Kaznowski, A. (2005). Polymorphism of Aeromonas spp. tRNA intergenic spacers. Syst Appl Microbiol 28, 222-229.

La Scola, B., Zeaiter, Z., Khamis, A. \& Raoult, A. (2003). Genesequence-based criteria for species definition in bacteriology: the Bartonella paradigm. Trends Microbiol 11, 318-321.

Liu, H., Li, Y., Huang, X., Kawamura, Y. \& Ezaki, T. (2003). Use of the dnaJ gene for the detection and identification of all Legionella pneumophila serogroups and description of the primers used to detect $16 \mathrm{~S}$ rDNA gene sequences of major members of the genus Legionella. Microbiol Immunol 47, 859-869.

Marmur, J. (1961). A procedure for the isolation of deoxyribonucleic acid from microorganisms. J Mol Biol 3, 208-218.

Martin-Carnahan, A. \& Joseph, S. W. (2005). Genus I. Aeromonas Stanier 1943, 213 ${ }^{\mathrm{AL}}$. In Bergey's Manual of Systematic Bacteriology, 2nd edn, vol. 2, part B, pp. 557-578. Edited by D. J. Brenner, N. R. Krieg, J. T. Staley \& G. M. Garrity. New York: Springer.

Martínez-Murcia, A. J. (1999). Phylogenetic positions of Aeromonas encheleia, Aeromonas popoffii, Aeromonas DNA hybridization group 11 and Aeromonas group 501. Int J Syst Bacteriol 49, 1403-1408.

Martínez-Murcia, A. J., Esteve, C. \& Collins, M. D. (1992a). Aeromonas allosaccharophila sp. nov., a new mesophilic member of the genus Aeromonas. FEMS Microbiol Lett 91, 199-206.

Martínez-Murcia, A. J., Menlloch, S. \& Collins, A. D. (1992b). Phylogenetic interrelationships of members of the genera Aeromonas and Plesiomonas as determined by $16 \mathrm{~S}$ ribosomal DNA sequencing: lack of congruence with results of DNA-DNA hybridizations. Int J Syst Bacteriol 42, 412-421.

Martínez-Murcia, A. J., Soler, L., Saavedra, M. J., Chacón, M. R., Guarro, J., Stackebrandt, E. \& Figueras, M. J. (2005). Phenotypic, genotypic, and phylogenetic discrepancies to differentiate Aeromonas salmonicida from Aeromonas bestiarum. Int Microbiol 8, 259-269.

Miñana-Galbis, D., Farfán, M., Fusté, M. C. \& Lorén, J. G. (2004). Aeromonas molluscorum sp. nov., isolated from bivalve molluscs. Int J Syst Evol Microbiol 54, 2073-2078.

Morandi, A., Zhaxybayeva, O., Gogarten, J. P. \& Graf, J. (2005). Evolutionary and diagnostic implications of intragenomic heterogeneity in the 16S rRNA gene in Aeromonas strains. J Bacteriol 187, 6561-6564.

Pidiyar, V., Kaznowski, A., Narayan, N. B., Patole, M. \& Shouche, Y. S. (2002). Aeromonas culicicola sp. nov., from the midgut of Culex quinquefasciatus. Int J Syst Evol Microbiol 52, 1723-1728.

Saavedra, M. J., Figuera, M. J. \& Martínez-Murcia, A. J. (2006). Updated phylogeny of the genus Aeromonas. Int J Syst Evol Microbiol 56, 2481-2487.

Saitou, N. \& Nei, M. (1987). The neighbor-joining method: a new method for reconstructing phylogenetic trees. Mol Biol Evol 4, 406-425.

Soler, L., Yáñez, M. A., Chacon, M. R., Aguilera-Arreola, M. G., Catalán, V., Figueras, M. J. \& Martínez-Murcia, A. J. (2004). Phylogenetic analysis of the genus Aeromonas based on two housekeeping genes. Int J Syst Evol Microbiol 54, 1511-1519.

Stackebrandt, E., Frederiksen, W., Garrity, G. M., Grimont, P. A. D., Kämpfer, P., Maiden, M. C., Nesme, X., Rosselló-Mora, R., Swing, J. \& other authors (2002). Report of the ad hoc committee for the reevaluation of the species definition in bacteriology. Int J Syst Evol Microbiol 52, 1043-1047.

Takewaki, S., Okuzumi, K., Manabe, I., Tanimura, M., Miyamura, K., Nakahara, K., Yazaki, Y., Ohkubo, A. \& Nagai, R. (1994). Nucleotide sequence comparison of the mycobacterial dnaJ gene and PCRrestriction fragment length polymorphism analysis for identification of mycobacterial species. Int J Syst Bacteriol 44, 159-166.

Thompson, J. D., Higgins, D. G. \& Gibson, T. J. (1994). CLUSTAL W: improving the sensitivity of progressive multiple sequence alignment through sequence weighting, position-specific gap penalties and weight matrix choice. Nucleic Acids Res 22, 4673-4680.

Yáñez, M. A., Catalán, V., Apráiz, D., Figueras, M. J. \& MartínezMurcia, A. J. (2003). Phylogenetic analysis of members of the genus Aeromonas based on gyrB gene sequences. Int J Syst Evol Microbiol 53, 875-883. 